\title{
Natural Frequencies of the Aqueduct Effected by Water Level
}

\author{
K.B. Ren \\ Henan Provincial Architectural Heritage Protection and Research Institute \\ Zhengzhou, China
}

\author{
Y.F. Zhu \\ North China University of Water Resources and Electric \\ Power, Zhengzhou, China \\ G. Zhao \\ Henan Provincial Architectural Heritage Protection and \\ Research Institute \\ Zhengzhou, China
}

\begin{abstract}
In design of aqueduct structure, natural frequency calculation is the basis of earthquake response analysis. In this paper, the dynamic characteristic of Gegou $U$ shape aqueduct is calculated by the finite element software ANSYS. And in this software, the interaction between water and aqueduct wall is simulated with added mass method. Natural vibration frequencies and principal modes of Gegou $U$ shape aqueduct are analyzed and calculated in four different water level which include empty tank water level, semi tank water level, design water level and bank-full water level. The calculation results show that the water level has a great influence on the natural frequencies of the aqueduct and the frequencies decrease with the increase of water level. The research results can provide basis for its protection and seismic design of $U$ shape aqueduct.
\end{abstract}

Keywords-Gegou aqueduct; ANSYS; natural frequency; vibration mode; added mass

\section{INTRODUCTION}

In China, distribution of water resources is extremely uneven, so inter-basin water transfer project has become an important content of China's water conservancy construction[1]. Therefore, it is particularly important to analyze dynamic characteristics of the aqueduct. Dynamic characteristics of large aqueduct structures include the frequencies and vibration modes[2]. In this paper, Gegou aqueduct of Liaoning is taken as the research object .Then we build three-dimensional finite element model of Gegou aqueduct by the finite element software ANSYS and calculate vibration frequency in the conditions of empty tank level, semi tank level, design level and bank-full level. The interaction between water and aqueduct wall is simulated with added mass method[3]. The results can provide a reference for the engineering design by Analyzing and Calculating vibration frequency and principal mode of Gegou aqueduct in different water level.

\author{
Q.Y. Chen \\ North China University of Water Resources and Electric \\ Power \\ Zhengzhou, China \\ W. He \\ North China University of Water Resources and Electric \\ Power \\ Zhengzhou, China
}

\section{ENGINEERING SITUATION}

Gegou aqueduct is located in Liaoning Province. Design discharge is $1.3 \mathrm{~m}^{3} / \mathrm{s}$; longitudinal slope is $1 / 650$ and the total length is $390 \mathrm{~m}$. This aqueduct is a simply supported beam. Aqueduct body is reinforced concrete structure, a U-shaped cross-section, and each section is $10 \mathrm{~m}$ long. The two ends of the aqueduct are put in Concrete bent.

\section{CAlCulation Model}

\section{A. Theoretical Calculation and Analysis}

According to the basic theory of structural dynamics, the equations of motion structure without damping vibration condition can be got as follow[4]:

$$
\boldsymbol{M} \ddot{\boldsymbol{u}}+\boldsymbol{K u}=0
$$

$M$ is the mass matrix; $K$ is stiffness matrix; $\ddot{u}$ is acceleration of node; $u$ is displacement of node.

Hypothesis:

$$
\boldsymbol{u}=\boldsymbol{\phi} \sin (\omega \mathrm{t}+\varphi)
$$

Then obtained:

$$
\ddot{\boldsymbol{u}}=-\omega^{2} \phi \sin (\omega \mathrm{t}+\varphi)
$$

As a result:

$$
\left(\boldsymbol{K}-\omega^{2} \boldsymbol{M}\right) \boldsymbol{\phi}=0
$$


$\omega$ is the natural frequency of the structure; $\phi$ is vibration mode.

\section{B. Model Parameters}

The concrete strength grade for aqueduct body of Gegou aqueduct is C30; Density is $2500 \mathrm{~kg} / \mathrm{m}^{3}$; Elastic modulus is 30GPa and Poisson's ratio is 0.1667[5].

\section{Finite Element Model}

Selecting SOLID 65 which is a 8 node 3D element to establish the three-dimensional finite element model of Gegou aqueduct. The element size is 0.05 , the number of element is 31504 , and the total number of nodes is 46941[6-7]. In the finite element calculation model of high-rise connected structure, $\mathrm{Y}$ direction is height direction, $\mathrm{Z}$ and $\mathrm{X}$ direction is horizontal, which shows in the Figure 1(The purple area is added mass).

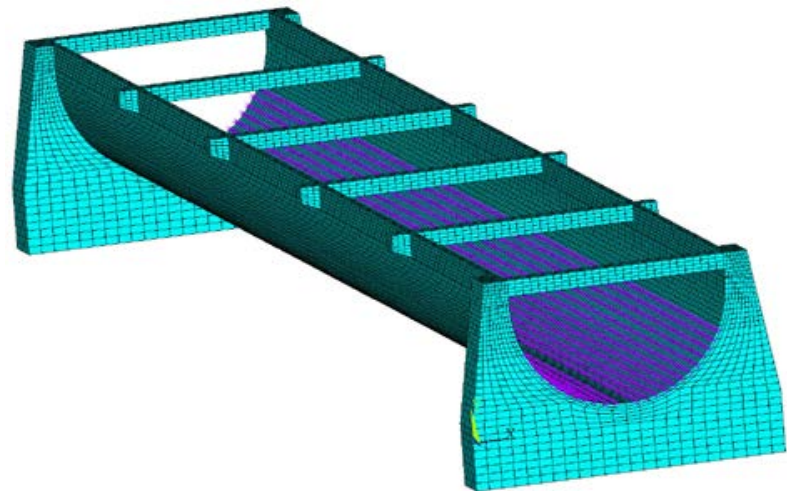

FIGURE I. FIGURE 1: FINITE ELEMENT CALCULATION MODEL OF GEGOU AQUEDUCT

\section{ANALYSIS OF CALCULATION RESULTS}

In engineering design, Low order mode is the most important of all vibration modes. First 6 order natural frequencies and vibration modes of Gegou aqueduct are taken to better illustrate the dynamic characteristics and changes of aqueduct structure. Vibration frequencies of aqueduct are shown in Table 1.To better illustrate the vibration form of aqueduct, the former six vibration modal map which is shown in Table 2 is taken when design water level. As can be seen from Table 1, with the depth increasing, the same order frequency is reduced.

TABLE I. THE FIRST 6 STEP NATURAL FREQUENCIES OF GEGOU U SHAPE AQUEDUCT (Hz).

\begin{tabular}{|c|c|c|c|c|}
\hline Step & $\begin{array}{c}\text { Empty } \\
\text { tank level }\end{array}$ & $\begin{array}{c}\text { Semi tank } \\
\text { level }\end{array}$ & $\begin{array}{c}\text { Design } \\
\text { level }\end{array}$ & $\begin{array}{c}\text { Bank-full } \\
\text { level }\end{array}$ \\
\hline $\mathbf{1}$ & 10.747 & 9.369 & 6.141 & 5.671 \\
\hline $\mathbf{2}$ & 19.490 & 14.506 & 10.588 & 10.069 \\
\hline $\mathbf{3}$ & 26.497 & 24.127 & 15.821 & 14.499 \\
\hline $\mathbf{4}$ & 40.579 & 32.822 & 23.843 & 22.554 \\
\hline $\mathbf{5}$ & 44.845 & 39.789 & 27.123 & 24.482 \\
\hline $\mathbf{6}$ & 49.938 & 40.239 & 28.885 & 27.116 \\
\hline
\end{tabular}

From the results known, The first order frequency is $10.747 \mathrm{~Hz}$ when empty tank level. The first order frequency is $9.369 \mathrm{~Hz}$ when semi tank level. The first order frequency is
$6.14 \mathrm{~Hz}$ when design level; The first order frequency is $5.671 \mathrm{~Hz}$ when bank-full level. Along with the deepening of the aqueduct water depth, the same order of frequency are decreasing. That is, the greater quality of water the aqueduct contained in, the lower the frequency. It also shows the power coupling body with the water tank has a significant effect on the aqueduct natural frequencies. As can be seen from Table 2, the first vibration mode is lateral-torsion. Second-order mode is vertical vibration. The lateral torsion of aqueduct appears firstly, which shows that lateral torsion stiffness is smaller. In order to overcome this drawback, the number of transverse brace can be appropriate to increase.

TABLE II. VIBRATION MODE OF GEGOU U SHAPE AQUEDUCT IN DESIGN WATER LEVEL

\begin{tabular}{|c|c|c|c|}
\hline Step & Modal map & Step & Modal map \\
\hline 1 & & & \\
\hline 3 & & & \\
\hline 5 & & & \\
\hline
\end{tabular}

\section{CONCLUSION}

The natural frequencies that are calculated in four different conditions show that the power coupling body and the water tank have a significant impact on the aqueduct natural frequencies. Therefore, water in tank must be considered when analyzing the dynamic characteristics and seismic response of aqueduct. While the vibration rule of the same order mode is similar, which shows that the vibration shape of whole structure is not affected by water in the aqueduct. The research results can provide basis for its protection and seismic design of $U$ shape aqueduct.

\section{ACKNOWLEDGEMENT}

This research was supported by the Science and Technology Program of Zhenzhou (No.20130844); the Foundation of Henan Educational Committee (No.13B130110 and 14A410005).

\section{REFERENCES}

[1] Xiaoqun Li, Yuan Zhang, Haishan Chen. Current situation and trend of development of domestic and foreign aqueduct. The Agricultural Science And Technology And Equipment, 12, 2011.

[2] ChunYang. Seismic response of frame-supported large rectangular aqueduct- water 3-D coupling system. Journal of Hydraulic Engineering, 36, 2005.

[3] Yisu Pan, Mingquan Zhong. The implementation of the added mass method in ANSYS.Computer Application, 23, 2003. 
[4] Ziming Zhang, Chengbin Du, (eds). Structural dynamics, Hohai University press: Nanjing, 2009.

[5] The Ministry of Water Resources of the People's Republic of China, (eds). Code for design of hydraulic concrete structures (SL191-2008). China Water Conservancy and Hydropower Press: Beijing, 2009.

[6] Bofang Zhu, (eds). Finite element method theory and application, China Water Conservancy and Hydropower Press: Beijing, 1998.

[7] Xinmin Wang, (eds). ANSYS numerical analysis of engineering structures, China Communications Press: Beijing, 2013. 